\title{
The Virtue of Gold as an Electrical Contact Material
}

\author{
AN EARLY DISCOVERY BY BENJAMIN FRANKLIN
}

\section{Bernard Caccia}

The outstanding properties of gold as a light-duty electrical contact material are so well appreciated, particularly in the electronics industry, that its use is accepted without question in circuits of many different types. But there had to be a first time for its advantages to be discovered and understood. This came about as long ago as 1747 , in the colonial days of North America, when that truly remarkable man printer, publisher, scientist, philosopher, and statesman - Benjamin Franklin, already at the height of his business activity in Philadelphia, not only found time to establish this property of gold but also grasped in a rudimentary form the concept of contact pressure and the importance of its effect on contact resistance.

Franklin's interest in electricity had been aroused when on a visit in $\mathbf{1 7 4 6}$ to his native Boston, where he attended a lecture and demonstration given by a Dr Spence from Scotland. "The experiments", he wrote, "were imperfectly performed, as he was not very expert; but, being on a subject quite new to me, they equally surprised and pleased me". He later purchased Spence's elementary apparatus and began experimenting for himself. His only source of electricity was a glass sphere or cylinder rotated by a crank and rubbing against a pad of leather or cloth, the charge so generated being drawn to a metal bar or chain suspended by strands of silk.

Today it is difficult indeed to realise the fundamental and perceptive nature of the experiments carried out by a small band of amateur scientists in Europe and America when their only source of the "electric fire" was electrostatic, before the days of continuous current from the Voltaic pile. In October 1745 Ewald Georg von Kleist, dean of the cathedral in the small Prussian city of Kammin (now Kamien-Pomorski in Poland) had hit upon a means of storing an electric charge in a small apothecary's phial with a nail driven into a wooden spool and inserted into the bottle. Almost simultaneously,

\section{Benjamin Franklin} 1706-1790

(from the portrait painted by Mason Chamberlain in 1762) in January 1746, Pieter van Musschenbroeck, Professor of Mathematics at Leyden University, discovered the same phenomenon, using a glass bottle filled with water and fitted with an iron wire dipping into the water and protruding through the cork.

This of course came to be known as the Leyden Jar, and among those who experimented with them in London was Peter Collinson, a Quaker cloth merchant and a Fellow of the Royal Society with whom Franklin had become friendly during his stay in London from 1724 to 1726 . A steady correspondence had been maintained over the years between the two, and very quickly Collinson sent over to Philadelphia one of the new and exciting pieces of apparatus. Franklin immediately had a number of jars made at a local glass works, and he and his circle of friends embarked on a series of experiments, but it was Franklin's characteristic energy and his total absorption in 'his investigations that carried him swiftly to a level of understanding that equalled or surpassed those of his distinguished contemporaries in Europe. He explained the operation of the Leyden

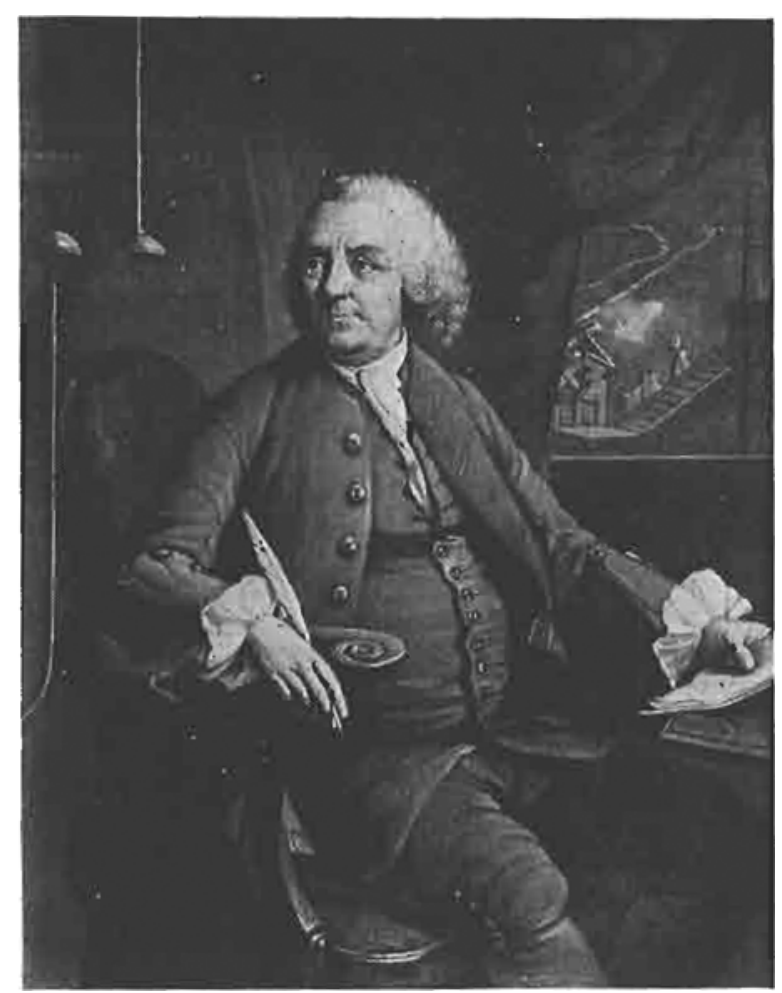




\section{LBTTBRS on BLECTRICITY.}

Take a book whofe cover is filletted with gold bend a wire of eight or ten inches long in the form of ( $m$ ) Frg. 5, llipit on the end of the cover of the book over the gold line, fo as that the houlder of it may prefs npon one end of the gold line, the ring up, but leaning towards the other end of the book. Lay the book on a glafs or wax; and on the other end of the gold lines, fet the bottle clectrifed : then bend the fpringing wire, by prefling it with a fick of wax till its ring approaches the ring of the bottle wire; inftantly there is a ftrong fpark and ftroke, and the whole line of gold, which completes the communication between the top and bottom of the bottle, will appear a vjvid flame, like the fharpeft lightning. The clofer the contact between the fhoulder of the wire, and the gold at one end of the line, and between the bottom of the bottle and the gold at the other end, the better the experiment fucceeds. The room thould be darkened. If you would have the whole filletting round the cover appear in fire at once, let the bottle and wire touch the gold in the diagonally oppofite corners.

$$
\text { I am, \&c: }
$$

\section{B. FRANKLIN.}

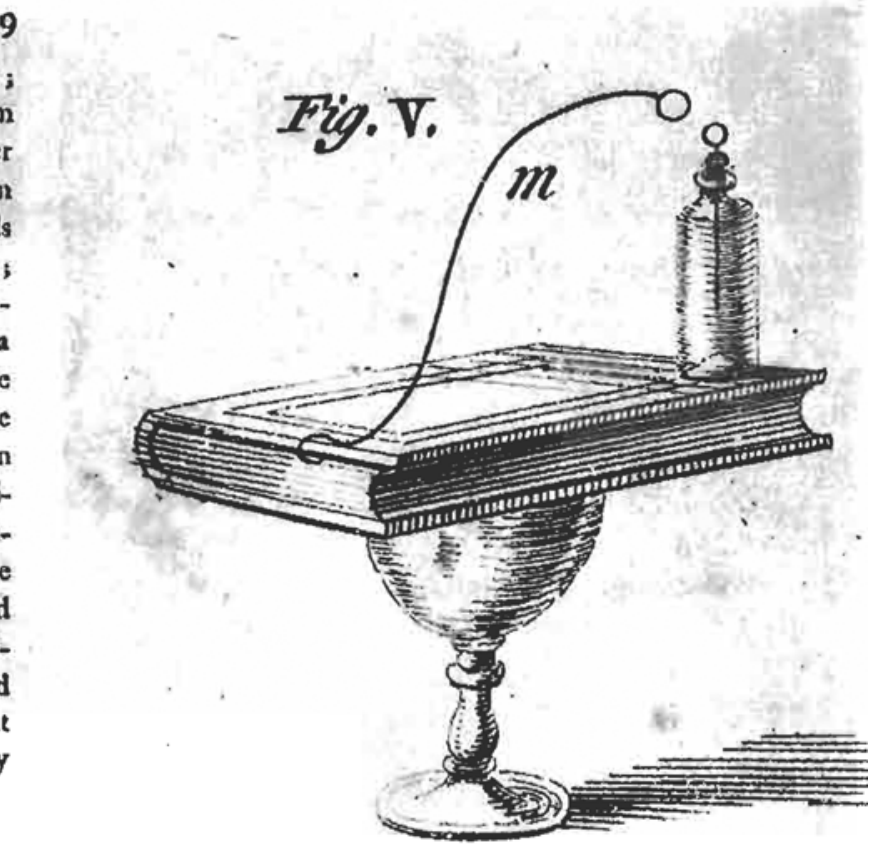

Franklin's letter of September 1st, 1747, to Peter Collinson describing the conducting and contact properties of gold. "The passing of the electrical fire from the upper to the lowcr part of the bottle", he wrote, "10 restore the equilibrium is rendered strongly visible by the following pretty experiment".

jar as a condenser, he introduced some of the terms we still use - positive, negative, plus and minus, conductor, and non-conductor - and of course he showed that lightning was an electrical display. But it is in one of his early experiments that we are interested in connection with gold.

All Franklin's studies were communicated by letter to Peter Collinson in London and were later published as Experiments and Observations on Electricity made at Philadelphia in America by $\mathrm{Mr}$ Benjamin Franklin, and communicated in several Letters to $M r P$. Collinson, of London, F.R.S. It is on September 1st, 1747 , in Letter 1, Experiment XI, reproduced here, that Franklin describes his "pretty experiment" with a book having gold filleting on the binding, coming to the conclusion that:

"The closer the contact between the shoulder of the wire, and the gold at one end of the line, and between the bottom of the bottle and the gold at the other end, the better the experiment will succeed.'

Nothing further is recorded on this initial observation of the contact properties of gold and in fact even the earliest and most elementary studies of electrical contact phenomena did not begin until well over a hundred years later.

ND I have further try'd, that with a small quantity of a certain Saline Substance
I prepar'd, I can easily enough sublime Gold into the form of red Chrystalls of a considerable length; and many other wayes may Gold be disguis'd, and help to constitute Bodies of very different Natures both from It and from one another, and nevertheless be afterwards reduc'd to the self-same Numerical, Yellow, Fixt, Ponderous and Malleable Gold it was before its commixture. 